\title{
Estudo das percepções de estudantes de engenharia sobre tecnologia social
}

\author{
StUdY OF THE PERCEPTIONS OF ENGINEERING STUDENTS ABOUt SOCIAL TECHNOLOGY
}

\author{
Brenda dos Santos Costa ${ }^{1}$, Bruna Sarpa Micell2 ${ }^{2}$ Pedro Miguel Marques da Costa 3 , Marcelo Borges Rocha ${ }^{4}$ \\ 1 - Graduanda em Engennharia Ambiental, Centro Federal de Educação Tecnológica Celso Sukow da Fonseca (Cefet/RJ), Rio de Janeiro, RJ, Brasil. \\ 2 - Doutoranda em Ciência, Tecnologia e Educação, Centro Federal de Educação Tecnológica Celso Sukow da Fonseca (Cefet/RJ), Rio de Janeiro, RJ, Brasil. \\ 3 - Doutorando em Clência, Tecnologia e Educação- Centro Federal de Educação Tecnológica Celso Sukow da Fonseca (Cefet/RJ), Rio de Janeiro, RJ, Brasil. \\ 4 - Docente no Centro Federal de Educação Tecnológica Celso Sukow da Fonseca (Cefet/RJ), Rio de Janeiro, RJ, Brasil.

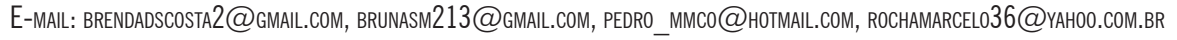

\begin{abstract}
Social Technology (ST) plays an important role by adopting different alternatives in favor of the environment and scientific and technological development. In addition, it promotes social inclusion and the active participation of the population. Thus, it is important to reinforce the role and understanding of different social actors about ST. This study aims to investigate students' perception from engineering courses at public and private institutions in the State of Rio de Janeiro about the concept of ST. An online questionnaire was applied to 399 students, and the data were analyzed in the light of Content Analysis. The results indicated that most students understand the TS applications, but do not present sustainable practices in their daily lives. It was concluded that the understanding of ST for the future engineer is necessary, as it will provide a better decision on issues related to social inclusion and sustainability.
\end{abstract}

Resumo: A Tecnologia Social (TS) desempenha um importante papel ao adotar diferentes alternativas em prol do meio ambiente e do desenvolvimento científico e tecnológico. Além disso, ela promove a inclusão social e a participação ativa da população. Deste modo, é importante reforçar o papel e a compreensão dos diferentes atores sociais sobre TS. Este estudo buscou investigar a percepção de estudantes de cursos de Engenharia de instituições públicas e privadas do Estado do Rio de Janeiro sobre o conceito de TS. Para isto, foi aplicado um questionário online para 399 estudantes e os dados foram analisados à luz da Análise de Conteúdo. Os resultados indicaram que grande parte dos estudantes compreendem as aplicações da TS, porém não apresentam práticas sustentáveis em seu cotidiano. Conclui-se que a compreensão sobre TS para o futuro engenheiro é necessária, pois proporcionará uma melhor decisão quando for aplicada a questões relacionadas à inclusão social e sustentabilidade.
Citation/Citação: Costa, B. S., Miceli, B. S., Costa, P. M. M. da, \& Rocha, M. B. (2021). Estudo das percepções de estudantes de engenharia sobre tecnologia social. Terræ Didatica, 17(Publ. Contínua), 1-9, e021033. doi: 10.20396/td.v17i00.8666328.

Keywords: Social inclusion, Environment, Questionnaire.

Palavras-chave: Inclusão social, Meio ambiente, Questionário.

\section{Manuscript/Manuscrito:}

Received/Recebido: 17/07/2021

Revised/Corrigido: 23/09/2021

Accepted/Aceito: 27/09/2021

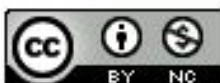

\section{Introdução}

O termo Tecnologia Apropriada (TA) ficou conhecido como uma tecnologia que visava combater problemas locais de maneira simples, além de gerar renda ou melhorias para a população. Seu surgimento foi influenciado pela necessidade de se atentar aos impactos das produções industriais e pelo fato de o desenvolvimento econômico e tecnológico não levar necessariamente apenas à benefícios sociais. Contudo, a TA também gerou consequências, dentre elas destacam-se a exclusão social e a degradação ambiental. Devido a esses problemas, surge, na década de 1980, o conceito de Tecnologia Social (TS), aprimorando-se o conceito e os pressupostos da TA, com um viés mais sustentável e participativo em comunidades locais (Rodrigues \& Barbieri, 2008).

Vale a pena ressaltar que a TS pode ser conceituada de diversas maneiras, sendo considerada um termo polissêmico. No entanto, de acordo com o Instituto de Tecnologia Social (ITS), ela é entendida como "um conjunto de técnicas, metodologias transformadoras, desenvolvidas e/ou aplicadas na interação com a população e apropriadas por ela, que representam soluções para a inclusão social e melhoria das condições de vida”. Em outras palavras, essa tecnologia consegue alterar ou trabalhar uma realidade social a partir de um projeto ou de um estudo social. Sendo assim, a TS é voltada para inclusão e transformação social, envolve o cotidiano

\begin{tabular}{c|c|c|c|c|c}
\hline (C) Terrae Didat. & Campinas, SP & v.17 & $1-9$ & $\mathrm{e} 021033$ & 2021 \\
\hline
\end{tabular}


e a participação da população e traz um impacto positivo para um mundo sustentável sem estar vinculada ao lado digital, como se costuma associar (RTS, 2009). Além disso, a proposta de TS vai contra a ideia de que desenvolvimento tecnológico e crescimento econômico estão associados apenas a benefícios sociais (Dagnino et al., 2002).

Segundo Otterloo (2009), a importância da TS está relacionada ao fato de ser desenvolvida em diversas áreas voltadas a demandas básicas humanas, como a educação, saúde, segurança, alimentação, energia, acessibilidade, e o meio ambiente. Ela pode ser aplicada em técnicas de coleta e armazenamento de água e no uso de energia com fontes alternativas, como por exemplo, a energia solar. Outra utilização da TS é através da alimentação como formas alternativas de se processar, conservar e cozinhar os alimentos com uma refrigeração em potes de barro, ou com o fogão a lenha otimizado, o Rocket Stove. Outras aplicações podem ser observadas em construções de moradias como, por exemplo, a bioconstrução e a fossa séptica. As características apresentadas mostram o quanto a TS está voltada para uma produção social e não de mercado, além de estar relacionada às realidades das populações locais, já que ela possibilita soluções mais adequadas aos problemas (Novaes \& Dias, 2009). Desta forma, um dos objetivos da TS é reverter a tendência vigente da tecnologia capitalista convencional.

Complementando essa discussão, Dagnino et al. (2004, p.15) afirmam que "a inovação não pode ser pensada em algo feito num lugar e aplicado em outro, mas como um processo desenvolvido no lugar onde essa tecnologia vai ser utilizada pelos atores que irão utilizá-las”. Esta informação abordada pelos autores consiste em um dos diferenciais da TS, devido aos estudos terem um certo envolvimento com a população local em diversas áreas, conhecendo o local como um todo, onde fosse possível atuar desde os problemas até as riquezas locais.

Com base no exposto, este estudo tem como objetivo investigar a percepção de estudantes de Engenharia de instituições públicas e privadas do Estado do Rio de Janeiro sobre o conceito de TS. Destaca-se a relevância deste estudo visto a importância do Engenheiro, especialmente quando se trata de TS, pois a profissão abrange muitas áreas de atuação; de modo geral, seu papel é elaborar e executar projetos em prol da resolução de problemas, sendo muitos deles de cunho socioambiental. Nesse sentido, em concordância com Dagnino e Novaes (2008, p.101), o Engenheiro desempenha um papel importante já que pode atuar na "transição rumo a uma sociedade que tenha como meta a satisfação das necessidades humanas".

\section{Metodologia}

Este estudo consiste em uma pesquisa qualitativa, que permite a compreensão e descrição de fenômenos de um determinado grupo de interesse, como atitudes, valores e comportamentos (Bauer \& Gaskell, 2017). Para a coleta de dados, foi utilizado um questionário online. A opção pela aplicação deste tipo de questionário, justifica-se pelo fato da pesquisa ter sido desenvolvida durante os meses de fevereiro e abril de $2021 \mathrm{em}$ meio à pandemia da COVID-19. Vale a pena lembrar que este instrumento é uma técnica de investigação que foi criada para recolher informações baseando-se, geralmente, na inquisição de um grupo representativo da população de estudo (Gil, 2002). O questionário foi aplicado a estudantes de Engenharia de instituições públicas e privadas do Estado do Rio de Janeiro e continha 32 perguntas, sendo sete abertas e 25 fechadas. Antes de ser aplicado, o questionário foi validado por um grupo de cinco estudantes de Engenharia que integram o laboratório de pesquisa no qual o estudo foi desenvolvido. Após as sugestões, o questionário foi elaborado na plataforma Google Forms, e em seguida divulgado em redes sociais, como Instagram, Whatsapp, Facebook e Linkedln.

Salienta-se que as perguntas foram apresentadas em três seções de investigação. A primeira buscou a compreensão do perfil dos estudantes, já na segunda seção, foram abordados os hábitos e costumes diários, tendo como objetivo obter informações sobre as ações cotidianas dos estudantes de engenharia. Por fim, a terceira seção buscou compreender o conceito e aplicação da TS por parte dos estudantes e se suas percepções sobre o termo mudaram após a aplicação do questionário.

As questões abertas do questionário foram analisadas de acordo com a Análise Categorial Temática de Bardin (1977). Para a criação das categorias de análise, três etapas foram seguidas: a pré-análise, exploração do material e tratamento dos resultados, e a inferência e a interpretação. A primeira etapa consiste na organização do material, etapa em que são avaliados todos os documentos por meio de um levantamento do que pode ou não ser aproveitado. Na segunda etapa há a categorização, ou seja, a criação de categorias de análise; por fim, a terceira

\begin{tabular}{c|c|c|c|c|c}
\hline (C) Terrae Didat. & Campinas, SP & v.17 & $1-9$ & $\mathrm{e} 021033$ & 2021 \\
\hline
\end{tabular}


etapa consiste na análise e interpretação dos dados da categoria (Câmara, 2013).

Vale lembrar que a Análise de Conteúdo é utilizada com o intuito de fornecer indicadores úteis aos objetivos da pesquisa. $\mathrm{O}$ pesquisador poderá ter uma interpretação dos resultados obtidos relacionando-o ao próprio contexto de produção do documento e aos objetivos do indivíduo ou organização/instituição que o elaborou (Oliveira et al., 2003).

\section{Resultados e discussão}

\section{Perfil dos estudantes}

Ao todo, a pesquisa contou com a participação de 399 estudantes, sendo 176 (44,1\%) do gênero feminino e 223 (55,9\%) do gênero masculino. No que diz respeito à faixa etária, 291 participantes (72,9\%) tinham entre 18 e 25 anos, 106 (26,6\%) possuíam 25 anos ou mais, e apenas dois respondentes $(0,5 \%)$ eram menores de 18 anos. Com relação à região de residência, 344 participantes $(86,2 \%)$ relataram que residem na região Metropolitana do Estado do Rio de Janeiro. Segundo Lombardi (2005), os setores profissionais vêm apresentando um aumento de atividades femininas, em especial na engenharia. Este campo contém uma linha histórica, onde por muito tempo o gênero masculino foi predominante. No entanto, ainda se percebe uma predominância do gênero masculino, apesar da área ter se tornado heterogênea e não estar mais restrita a um gênero.

Quanto às universidades, notou-se que 329 estudantes $(82,4 \%)$ pertenciam às universidades públicas e 70 $(17,6 \%)$ às universidades particulares. Dentre as universidades públicas, o Centro Federal de Educação Tecnológica Celso Suckow da Fonseca (CEFET/ $\mathrm{RJ}$ ) foi a que mais apresentou respondentes, seguido pela Universidade Federal Fluminense (UFF) (Fig.1).

Com relação aos cursos de Engenharia, notou-se que a maio2021
Universidades Públicas e Privadas

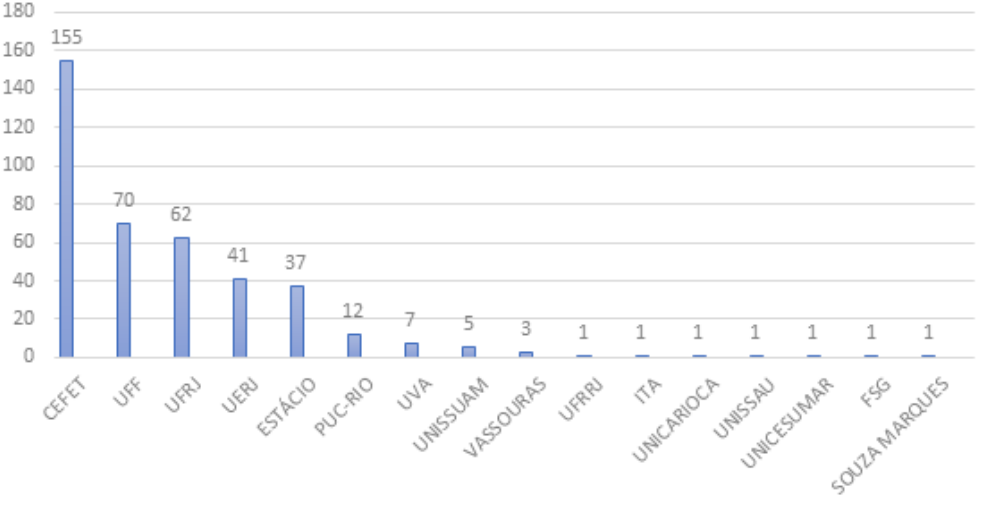

Figura 1. Distribuição de universidades públicas e privadas por participantes. Fonte: os autores, 2021

ria dos participantes era da Engenharia de Produção, com 94 respondentes (23,6\%). A Engenharia Ambiental foi a segunda mais citada, com 69 (17,3\%) estudantes (Fig. 2).

Ainda com relação ao perfil dos estudantes, a predominância no ano de ingresso nas instituições foi o de 2019.1, com 52 respondentes (13\%), seguido de 2017.1 com 47 respondentes $(11,8 \%)$, 2017.2 com 43 (10,8\%), entre outros períodos. Este dado mostra que estes estudantes, em sua maioria, entraram recentemente para os cursos de Engenharia e que, portanto, ainda estão em fase inicial de construção de seu aprendizado. Além disso, vale lembrar que 240 estudantes $(60,2 \%)$ somente estudavam, 151 (37,8\%) trabalhavam e estudavam, e oito participantes (2\%) não responderam.

Foi perguntado aos estudantes se eles frequentavam ou já frequentaram algum tipo de formação adicional na área ambiental, como por exemplo extensões/cursos/iniciação científica. Assim, 252

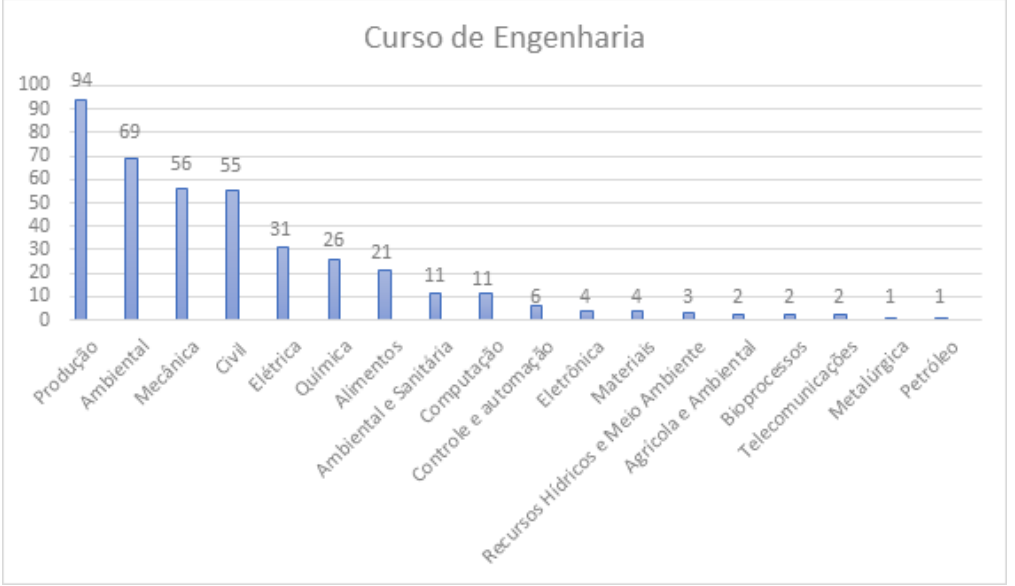

Figura 2. Cursos de graduação dos estudantes de Engenharia. Fonte: os autores,

\begin{tabular}{c|c|c|c|c|c}
\hline (C) Terrae Didat. & Campinas, SP & v.17 & $1-9$ & $\mathrm{e} 021033$ & 2021 \\
\hline
\end{tabular}


respondentes $(63,2 \%)$ afirmaram que frequentavam/frequentaram, e 147 (36,8\%) nunca tiveram este contato. Além da área de formação adicional, foi questionado sobre a participação dos estudantes em projetos sociais, e se os mesmos eram ou não da área ambiental. Como resposta, 211 participantes $(52,9 \%)$ afirmaram que não fizeram parte de projetos sociais, $140(35,1 \%)$ já fizeram parte de projetos sociais e apenas 48 (12\%) ainda faziam parte destes projetos. Vale a pena destacar que dentre esses estudantes que frequentavam ou que já frequentaram em algum momento projetos sociais, apenas 47 pessoas $(11,8 \%)$ relataram que os projetos sociais eram associados à área ambiental. Possivelmente esta parcela de estudantes está relacionada ao curso de Engenharia Ambiental, onde este contato com a área é ainda mais evidente. Segundo Martins (2008) a participação em projetos sociais, bem como projetos de extensão, são de extrema importância para formação pessoal e profissional do estudante, já que proporcionam a oportunidade de ampliar o conhecimento sobre a realidade de diferentes comunidades e compreender o seu papel enquanto sujeito social. Complementando esta informação, Coelho e Gonçalves (2011) afirmam que os projetos sociais são capazes de influenciar a realidade e de transformar os cenários, ou seja, de provocar mudanças positivas em uma determinada comunidade.

Por fim, foram feitas perguntas abertas aos estudantes sobre possíveis problemas ambientais na região em que moravam. Assim, 298 estudantes $(74,7 \%)$ identificaram impactos ambientais em suas regiões, 72 (18\%) não sabiam identificar, e 29 não identificavam (7,3\%). Acredita-se que estes problemas ambientais, em sua maioria, estejam relacionados aos avanços científicos e tecnológicos e à utilização da tecnologia convencional, que, diferente da TS, tem se tornado ambientalmente insustentável (Dagnino, 2004). Para a apresentação dos problemas ambientais mais citados pelos estudantes, foram criadas categorias como "Saneamento", "Poluição" e "Políticas públicas" (Tab.1).

Dentro de cada categoria foram criadas subcategorias, que serão abordadas a seguir. $\mathrm{Na}$ área de "Saneamento" a subcategoria que mais obteve resposta foi a "Limpeza urbana e manejo de resíduos sólidos", onde os problemas citados foram a falta de coleta, tratamento e destinação de resíduos, limpeza de lugares públicos, entre outros. A resposta dos seguintes participantes retratam estas questões: "Falta de coleta seletiva eficiente e transparente com a destinação dos resíduos (...)” (R73), “Acúmulo de
Tabela 1. Principais categorias a respeito de problemas da região do Estado do Rio de Janeiro. Fonte: os autores, 2021

\begin{tabular}{l|l}
\hline Categorias & Definições \\
\hline Saneamento & $\begin{array}{l}\text { Refere-se ao conjunto de servi- } \\
\text { cos, infraestrutura e instalações } \\
\text { operacionais. }\end{array}$ \\
\hline Poluição & $\begin{array}{l}\text { Categoria relacionada a ativida- } \\
\text { des capazes de causar danos ao } \\
\text { meio ambiente, sendo por ex- } \\
\text { cesso de liberação de poluentes, } \\
\text { matérias ou energia. }\end{array}$ \\
\hline Políticas Públicas & $\begin{array}{l}\text { Relaciona-se com a ação do } \\
\text { Estado envolvendo iniciativas } \\
\text { em prol do bem-estar da po- } \\
\text { pulação. }\end{array}$ \\
\hline
\end{tabular}

lixo nas ruas" (R257), "Excesso de lixo em locais abertos" (R264) e "Muito lixo no meu bairro, e o lixo fica exposto, a céu aberto" (R278).

Ainda na categoria de "Saneamento", a segunda subcategoria mais identificada foi a "Drenagem e manejo de águas pluviais", um campo que se destina à construção de instalações para finalidades como o escoamento e direcionamento de águas das chuvas: "Subdimensionamento da rede de esgoto e drenagem; despejo de esgoto ilegal (...)” (R1), "Alaga com facilidade em dias chuvosos” (R30), "(...) água potável, encanamentos sem destinos corretos; (...)” (R53), "Lixo em excesso ocasionando enchentes" (R221) e "Ocorre enchentes independente do volume de água” (R304).

Quanto à categoria "Poluição", a subcategoria mais citada foi "Poluição atmosférica", relacionada ao agravamento do efeito estufa e do aquecimento global. Um dos fatores que influenciam neste tipo de poluição é o crescente número de veículos, que geram impactos negativos no meio ambiente devido a emissão de gases poluentes: "Poluição do ar. Itha de calor (...)” (R34), “(...) alta emissão de gases poluentes oriundos da queima de combustiveis fósseis" (R35), "Poluição do ar ao excesso de veículos (...)” (R200), “(...) o uso frequente de automóveis que gera uma poluição na atmosfera." (R251), "Poluição atmosférica devido a emissão de gases estufa." (R349).

Outra subcategoria citada foi "Poluição da água", onde foi relatado sobre a poluição das águas por resíduos despejados em mares, rios, lagos e/ ou lagoas, por esgoto ou navios despejado indevidamente nessas águas, podendo gerar muitos problemas ambientais, principalmente a extinção de espécies locais: "Poluição da Baía de Guanabara;

\begin{tabular}{c|c|c|c|c|c}
\hline (C) Terrae Didat. & Campinas, SP & v.17 & $1-9$ & $\mathrm{e} 021033$ & 2021 \\
\hline
\end{tabular}


Assoreamento das lagoas de Itaipu e Piratininga (...)" (R87), "Poluição da lagoa de Piratininga, Niterói, descarte de esgoto de forma inadequada em praias como Icarai e Charitas." (R105), "Despejo de poluentes em rios e bacias (...)" (R148), e "Poluição de lixo e esgoto nos mares" (R333).

Na categoria de "Políticas Públicas", a subcategoria predominante foi "Gestão", que está relacionada a uma prática político-administrativa e tem como princípio incentivar a participação, a autonomia e a responsabilidade da população de um modo geral: "Má gestão ambiental tanto pelos órgãos públicos quanto pelos moradores" (R44), "Falta de (...) projetos ecológicos relacionados a descarte de lixo." (R85), "Falta de programa para reciclagem" (R231), "Falta de regulamentação e fiscalização de indústrias” (R234), e "(...) o alto tráfego de veículos, devido ao transporte público deficiente." (R102).

Para Tachizawa (2005), a falta de gestão e administração tornou necessário o desenvolvimento de projetos sociais e ambientais relacionados à TS em diversos contextos municipais. No entanto, para Paludo (2013) a falta de gestão pode ser revertida. Segundo o autor, a administração pública é capaz de superar as dificuldades, colocando em ação algumas soluções. Deste modo, todo recurso público deve ser planejado e sustentável, principalmente com relação a problemas sociais e a TS pode ser apresentada como uma solução eficiente.

As Políticas Públicas, segundo Pereira (2008), são organizadas de acordo com interesse comum, da comunidade, da soberania popular, e não da soberania dos que governam. Isto permite a participação da população nas tomadas de decisões sobre as políticas públicas, bem como o destino dos seus recursos, e devido a isso, a utilização de TS como políticas públicas seria uma possível mudança para diversos setores.

\section{Hábitos e costumes diários}

Esta segunda seção teve o intuito de investigar se os estudantes possuíam alguma preocupação ambiental em suas ações diárias e observar se suas atitudes são colocadas em prática, ou só ficam na teoria.

Com relação ao grau de concordância com a frase: "A separação seletiva deve começar em casa", 289 estudantes $(72,4 \%)$ concordaram totalmente com a frase, 77 (19,3\%) concordaram parcialmente, $21(5,3 \%)$ não concordaram e nem discordaram, três discordam parcialmente $(0,8 \%)$ e nove discordaram totalmente $(2,3 \%)$. Ainda relacionado a essa frase, os participantes foram questionados se realizavam a coleta seletiva em seu cotidiano. Apenas 81 pessoas $(20,3 \%)$ relataram realizar esta separação, 168 (42,2\%) não fazem e 150 participantes (37,6\%) realizam às vezes. Em outras palavras, observou-se que apesar da maioria concordar com as práticas de coleta seletiva, nem todos exercem essa atividade. A coleta seletiva é essencial para o desenvolvimento sustentável e tornou-se uma ação importante na vida moderna devido ao aumento do consumo e consequentemente do lixo produzido. Segundo Lima et al. (2011), a coleta seletiva é benéfica em muitos sentidos, evitando como por exemplo a disseminação de doenças contribuindo para que os resíduos tenham destino correto, além de gerar empregos para catadores de materiais recicláveis.

Posteriormente, foi perguntado sobre os principais hábitos adotados pelos estudantes e dentre as opções mais assinaladas estava a utilização de mais produtos orgânicos do que industrializados, com 188 respondentes (47,1\%). Além disso, 108 participantes $(27,1 \%)$ reaproveitam cascas de frutas/ legumes em outras receitas e 107 (26,8\%) utilizam a composteira. Estas atitudes mostraram-se positivas, já que o resíduo orgânico é o material que mais está presente nos lixões. Ao reaproveitar esses resíduos, minimiza-se a quantidade de lixo, evita-se outros problemas ambientais e pode-se gerar adubo. No entanto, apesar destas atitudes positivas, outras opções também foram assinaladas: 121 estudantes (30,3\%) obtêm produtos em grande quantidade, onde corre-se o risco de gerar desperdícios e 109 pessoas $(27,3 \%)$ não escolheram nenhuma das opções abordadas.

Ao pensar na reutilização, apresentou-se a seguinte frase aos participantes da pesquisa: "Tudo que existe tem mais de uma função". A partir disso, notou-se que 207 estudantes (51,9\%) concordaram totalmente com esta afirmação, 159 $(39,8 \%)$ concordaram parcialmente, $25(6,3 \%)$ não concordaram e nem discordaram e seis estudantes $(1,5 \%)$ discordam parcialmente. Uma das formas de se promover o desenvolvimento sustentável é através da utilização dos $6 \mathrm{R}$ 's (reduzir, reutilizar, reciclar, recuperar, redesenhar e remanufaturar). Em outras palavras, obter uma consciência das consequências de suas ações, e ter uma preocupação com o ciclo de vida de cada produto é uma prática importante para a sustentabilidade por estar associada à redução e conservação dos recursos naturais (Finnveden, 2009, Jayal et al., 2010, Shuaib et al., 2014).

\begin{tabular}{c|c|c|c|c|c}
\hline (C) Terrae Didat. & Campinas, SP & v.17 & $1-9$ & $\mathrm{e} 021033$ & 2021 \\
\hline
\end{tabular}


Ainda nesta seção, abordou-se a opinião dos estudantes caso ocorresse uma escassez de água doce. Desta forma, 273 respondentes $(68,4 \%)$ acreditam que terá outros meios de transformar água salgada em doce, 81 (20,3\%) concordaram com a hipótese de que caso a água doce acabasse, ficaríamos sem água, 17 (4,3\%) consideram que não é necessário se preocupar com essa problemática e $28(7 \%)$ respondentes não souberam responder. Vale a pena lembrar que muitas alternativas associadas ao problema da escassez consistem em aplicações de TS. De acordo com Moghimi et al. (2018), pesquisadores descobriram um método comum para a dessalinização do mar partindo do uso de TS, utilizando o processo de dessalinização por destilação podendo ser aplicado o sistema térmico o dessalinizador de múltiplos efeitos (MED), sistema de dessalinização flash de múltiplos estágios (MSF), sistema de compressão de vapor (MVC) e o sistema de destilação solar (DS), gerando um bom alcance social por ter baixo custo e fácil aplicação.

\section{Percepção sobre tecnologia social}

A terceira seção buscou identificar a percepção dos estudantes sobre TS. Para isto, os participantes foram questionados sobre a relação do despejo de resíduos nos lixões e o processo de coleta seletiva. A alternativa mais assinalada foi que a coleta seletiva ajuda os catadores de materiais recicláveis e na destinação correta dos materiais, com 347 respostas (87\%), seguidos com $36(9 \%)$ que não concordavam com nenhuma das alternativas, $34(8,5 \%)$ afirmavam que a coleta seletiva serve exclusivamente para prevenir a emissão da quantidade de gás carbônico na atmosfera, 33 (8,3\%) assinalaram que a coleta seletiva é necessária, pois sem ela, somente a população da cidade é afetada, e $21(5,3 \%)$ assinalaram que os lixões são uma boa alternativa para o lixo não ficar nas cidades e não causar poluição visual.

A coleta seletiva é uma prática da TS na qual há um sistema de recolhimento de materiais recicláveis (papéis, plásticos, vidros, metais e orgânicos), que são previamente separados na fonte geradora e que podem ser reutilizados ou reciclados. A separação na fonte evita a contaminação dos materiais reaproveitáveis, aumentando o valor agregado destes e diminuindo os custos da reciclagem. Além disso, acrescenta-se que esta prática também pode gerar empregos. Quando esta separação seletiva é realizada em casa, ela torna-se essencial para ajudar os trabalhadores da coleta e sobretudo traz contribuições para a promoção de uma conscientização sustentável (Coelho, 2008).

Sobre as funções da reciclagem, 347 participantes $(87 \%)$ assinalaram a opção de que ela reduz a poluição ambiental, 306 (76,7 \%) marcaram que gera empregos, $60(15 \%)$ assinalaram todas as alternativas, $24(6 \%)$ assinalaram que ela aumenta a extração de recursos naturais, e duas pessoas $(0,5 \%)$ não assinalaram nenhuma das alternativas. Esta relação da reciclagem com a diminuição da poluição vai ao encontro do que afirma Horst e Freitas (2016). Segundo os autores, a importância da reciclagem está na preservação de recursos naturais, redução da poluição e da quantidade de resíduos nos aterros. Além disso, a reciclagem contribui para geração de empregos, devido a projetos relacionados à TS, trazendo consigo ganhos ambientais sociais com a inclusão de catadores.

Ainda nesta seção, foi sugerido que os estudantes assinalassem as opções que indicassem exemplos de TS, como pode ser observado na Tabela 2.

A partir dos dados acima, percebe-se que, de forma geral, os estudantes identificaram as aplicações da TS. No entanto, uma parcela desse público ainda associa a TS a um conceito mais tecnológico (como por exemplo os painéis solares e/

\begin{tabular}{c|c|c|c|c|c}
\hline (C) Terrae Didat. & Campinas, SP & v.17 & $1-9$ & $\mathrm{e} 021033$ & 2021 \\
\hline
\end{tabular}


ou biodigestores e criação de aplicativo) do que a opção de discutir políticas públicas. É de extrema importância lembrar que TS é relacionada a alguns produtos, técnicas e metodologias reaplicáveis que são desenvolvidas por meio de um envolvimento da comunidade, visando um incentivo social e um resultado mais efetivo (Franzoni \& Silva, 2016).

Os estudantes também foram questionados sobre suas percepções a respeito da função da fossa séptica. Destaca-se que ela é entendida como uma alternativa comumente utilizada em pequenas comunidades rurais, onde preza o saneamento básico, reduzindo os riscos de doenças ligadas à insalubridade sem colocar o solo e as águas subterrâneas em risco (Withers et al., 2011). Notou-se que 194 respondentes $(48,6 \%)$ assinalaram a opção dela servir para a implementação de um sistema de baixo custo e aplicação, seguido de 185 participantes $(46,4 \%)$ que afirmam que essa técnica garante o saneamento básico, evitando vetores e a proliferação de doenças, 170 (42,6\%) que responderam que evitava a contaminação de lençóis freáticos e mananciais, $70(17,5 \%)$ assinalaram que ela é utilizada para reaproveitamento de espaço usando para plantação de hortaliças e 140 (35,1\%) não souberam responder.

A partir destes dados percebe-se que as alternativas assinaladas correspondem aos objetivos de uma fossa séptica. De acordo com Archanjo Junior e Gehlen (2020) as fossas sépticas são uma das principais demandas sociais existentes e sua instalação possibilita o envolvimento da população em todo o processo. Em outras palavras, o envolvimento dos moradores possibilita que eles desenvolvam uma maior compreensão sobre o tema e sobre a importância de tal instalação. Complementando esta informação, Costa e Guilhoto (2014) também destacam que as fossas sépticas reduzem os riscos de doenças ligadas à insalubridade, podem promover empregos e diminuem o risco de poluição da água.

Foi questionado se a TS poderia ser realizada com baixo investimento. Notou-se que 282 respostas $(70,7 \%)$ afirmaram que sim, seguidas de 88 participantes $(22,1)$ que não sabiam como poderia ser realizado este investimento. A maioria das respostas dos estudantes vai ao encontro do que afirma Dagnino (2004), onde a TS pode ser adaptada ao reduzido tamanho físico e financeiro, priorizando a sustentabilidade e a população com a parte econômica.

Os estudantes também foram questionados sobre a utilização de resíduos orgânicos. Desta forma, algumas respostas se destacaram: "Utilizo cascas e restos de alimentos como adubo para plantação de hortaliças." (R99), "Sim, de alimentos fazendo produtos de higiene como por exemplo sabonete" (R254), "Sim, tenho composteira" (R203), "A maioria é para cultivo de pequenas plantações que tenho em casa" (R122), "Sim, faço o uso nas plantas como fontes de nutrientes e para o consumo próprio tento não desperdiçar nada." (R221). Apesar de alguns estudantes relatarem que não utilizavam estes resíduos, a maioria revelou compreender a sua importância e gostariam de poder utilizá-los. Isto fica evidente nas seguintes frases: "Não, mas sei que pode ser usado como adubo." (R109), "Não, sempre quis fazer uma composteira mas não possuo espaço em minha residência." (R256).

A compostagem é uma técnica que vai ao encontro da Política Nacional de Resíduos Sólidos, sendo definida como uma forma de destinação final. É possível aplicar práticas de compostagem em diferentes escalas, e junto com a prática de TS possibilita-se aplicar modelos de compostagens de baixo custo, fácil aplicabilidade, além de gerar benefícios gerando renda, inclusão, incentivos ao empreendedorismo, e à educação ambiental, com compostagens comunitárias, por exemplo (Brasil, 2010).

Outro ponto abordado nesta seção estava relacionado com o conceito de Economia Solidária e TS. A opção apresentada, considerada como Economia Solidária, foi a de 'trocas de bens e serviços', com 176 respondentes $(44,1 \%)$, 'conjunto de práticas econômicas de produção, logística e consumo', com 161 (40,4\%), 'tudo que é voltado para a população e não está relacionado com o lucro', com 117 respostas (29,3\%). Destaca-se que 135 participantes $(33,8 \%)$ não sabiam o que era Economia Solidária, e seis $(1,5 \%)$ acreditavam que priorizava o capital financeiro.

Segundo Adams (2010), a economia solidária procura distinguir normas e valores da economia capitalista pela gestão coletiva, baseado na propriedade ou na gestão social dos meios de produção. $\mathrm{O}$ controle do poder de decisão pertence aos associados do empreendimento solidário, com igualdade de direitos. A Economia solidária é considerada como uma TS já que os próprios trabalhadores gerenciam e organizam coletivamente o processo produtivo, sendo deles o poder de destinar o restante e o excesso produzido.

Por último, os alunos foram indagados se a sua percepção sobre TS havia mudado após o questionário. Pôde-se notar que grande parte dos partici-

\begin{tabular}{c|c|c|c|c|c}
\hline (C) Terrae Didat. & Campinas, SP & v.17 & $1-9$ & $\mathrm{e} 021033$ & 2021 \\
\hline
\end{tabular}


pantes afirmaram que mudou especialmente pelo fato do questionário ter despertado curiosidade de aprendizado e reflexões sobre suas ações diárias. Isto fica evidente no seguinte trecho: "Mudou, expandiu a minha visão sobre o assunto, o tema é complexo e abrange várias áreas da nossa sociedade e busca conciliar com a preservação ambiental. Podendo ser um projeto trabalhado em pequenas ou grandes ações." (R4).

Ademais, foi possível perceber que para alguns estudantes, tal tema ainda era desconhecido, o que reforça ainda mais a necessidade de se discutir e inserir estas questões nos cursos de Engenharia: "Sim, apresentou novos conceitos e novas reflexões, como a "economia solidária", que não conhecia antes." (R166) e "Sim. Ainda desconhecia o conceito e suas implicações." (R188).

\section{Conclusão}

A Tecnologia Social constitui uma nova alternativa a favor do ambiente e do desenvolvimento científico e tecnológico. Além disso, ela possibilita a inclusão e transformação social, já que envolve o cotidiano e a participação da população. Assim, é importante reforçar o papel e a compreensão do Engenheiro sobre TS, pois o profissional atua diretamente com a relação existente entre ciência, tecnologia e sociedade.

Com relação ao questionário aplicado aos estudantes de Engenharia, percebeu-se que é um público heterogêneo, com diferentes faixas etárias e condições sociais. Ao investigar sobre os hábitos e costumes diários, notou-se que uma grande parcela dos estudantes tinha conhecimento das ações que ajudariam de alguma forma o meio ambiente, porém quando as perguntas estavam se referindo à realização de suas ações, era possível perceber que tais estudantes não tinham o costume de aplicá-las em seu cotidiano. Já com relação ao conceito de TS, percebeu-se que, em geral, os estudantes compreenderam os conceitos e aplicações com o questionário aplicado. Com relação aos estudantes que não conheciam o conceito de TS pôde-se notar que o questionário gerou curiosidade sobre a temática. O questionário contribuiu para que os estudantes fizessem reflexões e/ou conhecessem novos temas que permeiam a sociedade. É importante refletir sobre a utilização e o manejo de diversos recursos, além de destacar o papel do futuro profissional de engenharia para que o conhecimento seja empregado ao longo de sua formação e do exercício de seu trabalho.

\section{Agradecimentos}

Os autores agradecem ao Conselho Nacional de Desenvolvimento Científico e Tecnológico (CNPq) e à Coordenação de Aperfeiçoamento de Pessoal de Nível Superior (CAPES) pelo apoio à pesquisa.

\section{Referências}

Adams, T. (2007). Educação e economia (popular) solidária: mediações pedagógicas do trabalho associado na Associação dos Recicladores de Dois Irmãos, 1994-2006. São Leopoldo, Universidade do Vale do Rio do Sinos. (Tese, Doutorado).

Archanjo Junior, M. G. \& Gehlen, S. T. (2020). A Tecnologia Social e sua Contribuição para a Educação em Ciências. Revista Brasileira de Pesquisa em Educação em Ciências, 20, 345-374. doi: 10.28976/1984-2686rbpec2020u345374.

Bardin, L. (1977). Análise de conteúdo. Lisboa: Edições 70.

Brasil. Ministério do Meio Ambiente. Secretaria de Recursos Hídricos e Ambiente Urbano. (2010). Manual para Implantação de Compostagem e de Coleta Seletiva no Âmbito de Consórcios Públicos. Brasília, DF.

Bauer, M. W., \& Gaskell, G. (2017). Pesquisa qualitativa com texto, imagem e som: um manual prático. Petrópolis: Vozes.

Câmara, R. H. (2013). Análise de conteúdo: da teoria à prática em pesquisas sociais aplicadas às organizações. Gerais: Revista Interinstitucional de Psicologia, 6(2), 179-191. URL: http://pepsic.bvsalud.org/pdf/ gerais/v6n2/v6n2a03.pdf. Acesso 06.05.2021.

Coelho, M. (2008). Coleta seletiva na escola no condomínio na empresa na comunidade no município. Secretaria do Meio Ambiente, São Paulo. URL: https:/www.infraestruturameioambiente.sp.gov.br/cea/2008/08/ coleta-seletiva-escola-condominio-empresa-comunidade-municipio/. Acesso 23.05.2021.

Coelho, Q. M. \& Gonçalves, A. C. (2011). Avaliação de projetos sociais: a perspectiva da comunidade. Revista Alcance, 18(4), 436-447. doi: 10.14210/alcance. v18n4.p436-447.

Costa, C. C. D., \& Guilhoto, J. J. M. (2014). Saneamento rural no Brasil: impacto da fossa séptica biodigestora. Engenharia Sanitária e Ambiental, 19, 51 60. doi: 10.1590/S1413-41522014019010000171.

Dagnino, R., Gomes, E., Costa, G., \& Stefanuto, G. (2002). Gestão estratégica da inovação: metodologias para análise e implementação. Taubaté: Cabral Universitária.

Dagnino, R. (2004). A tecnologia social e seus desafios. Tecnologia social: uma estratégia para o desenvolvimento. Rio de Janeiro: Fundação Banco do Brasil. p. 187209.

Dagnino, R., Brandão, F. C., \& Novaes, H. T. (2004). Sobre o marco analítico-conceitual da tecnologia social. Tecnologia social: uma estratégia para o desenvolvimento. Rio de Janeiro: Fundação Banco do Brasil. p. 65-81.

Dagnino, R., \& Novaes, H.T. (2008). O papel do en- 
genheiro na sociedade. Revista Tecnologia e Sociedade, 4(6), 95-112.

Franzoni, G. \& Silva, T. (2016). Inovação Social e Tecnologia Social: o caso da Cadeia Curta de Agricultores Familiares e a Alimentação Escolar em Porto Alegre/RS. Desenvolvimento em questão, 14(37), 353 386. doi: 10.21527/2237-6453.2016.37.353-386.

Finnveden, G., Hauschild, M. Z., Ekvall, T., Guinée, J., Heijungs, R., Hellweg, S., Koehler, A., Pennington, D., \& Suh, S. (2009). Recent developments in Life Cycle Assessment. Journal of Environmental Management, 91(1), 1-21. doi: 10.1016/j.jenvman.2009.06.018.

Gil, A. C (2002). Como elaborar projetos de pesquisa. 4 ed. São Paulo: Atlas.

Jayal, A.D, Badurdeen, O.W, Dillon Jr., O.W. \& Jawahir, I.S. (2010). Sustainable Manufacturing: Modeling and Optimization of Indicators for Sustainable Manufacturing. Cirp Journal of Manufacturing Science and Technology, 2, 144-152.

Horst, L. V. M., \& Freitas, C. C. G. (2016). Desenvolvimento sustentável e inovação social: a reciclagem sob a perspectiva da tecnologia social. Revista Tecnologia e Sociedade, 12(26), 20-41. doi: 10.3895/rts. v12n26.3787.

Lima, F. D. P. A., Varella, C. V. S., Oliveira, F. G. D., Parreiras, G., \& Rutkowski, J. (2011). Tecnologias sociais da reciclagem: efetivando políticas de coleta seletiva com catadores. Gerais: Revista Interinstitucional de Psicologia, 4(SPE), 131-146. URL: http:// pepsic.bvsalud.org/pdf/gerais/v4nspe/v4nspea04. pdf. Acesso 21.05.2021.

Lombardi, M. R. (2005). Perseverança e resistência: a engenharia como profissão feminina. Campinas, Universidade Estadual de Campinas, Faculdade de Educação. 286p. Tese (doutorado).

Martins, E. F. (2008). Extensão como componente curricular: oportunidade de formação integral e de solidariedade. Ciências \& Cognição, 13(2), 201209. URL: http://www.cienciasecognicao.org/revista/index.php/cec/article/view/232/131. Acesso 10.06.2021.

Moghimi, M., Emadi, M., Akbarpoor, A. M., \& Mollaei, M. (2018). Energy and exergy investigation of a combined cooling, heating, power generation, and seawater desalination system. Applied Thermal Engineering, 140, 814-827. doi: 10.1016/j.applthermaleng.2018.05.092.

Novaes, H. T., \& Dias, R. (2009). Contribuições ao marco analítico-conceitual da tecnologia social. In: Dagnino, R.T. Tecnologias sociais: ferramenta para construir outra sociedade. Campinas: Unicamp, 17-53.

Paludo, A. (2013). Administração Pública. 3 ed. Rio de Janeiro: Elsevier.

Otterloo, A. (2009). Tecnologias Sociais: Caminhos para a sustentabilidade. Brasília: Gráfica Brasil.

Oliveira, E. de, Ens, R. T., Freire Andrade, D. B. S., \& Mussis, C. R. (2003). Análise de conteúdo e pesquisa na área da educação. Revista Diálogo Educacional, 4(9), 1-17. doi: 10.7213/rde.v4i9.6479.

Pereira, J. M. (2008) Políticas públicas de educação no Brasil: a utilização da EAD como instrumento de inclusão social. Journal Technology Management $\mathcal{E}$ Innovation, 3(1), 44-55. URL: https://repositorio.uahurtado.cl/handle/11242/2121. Acesso 04.06.2021.

Rodrigues, I. \& Barbieri, C. J. (2008). A emergência da tecnologia social: revisitando o movimento da tecnologia apropriada como estratégia de desenvolvimento sustentável. Revista de administração Pública, 42(6), 1069-1094. doi: 10.1590/S003476122008000600003 .

Rede de Tecnologia Social (RTS). (2009). Tecnologias Sociais: Caminhos para a sustentabilidade. Brasília: Gráfica Brasil.

Shuaib, M., Seevers, D., Zhang, X., Badurdeen, F., Rouch, K. E \& Jawahir, I. S. (2014). Product sustainability index: a metrics-based framework to evaluate the total life cycle sustainability of manufactures products. Journal of Industrial Ecology. 18(4), 491-501. doi: 10.1111/jiec.12179.

Tachizawa, T. (2005). Gestão ambiental e responsabilidade social corporativa: estratégia de negócios focados na realidade brasileira. São Paulo: Atlas.

Withers, P. J. A, Jarvie, H. P \& Stoate, C. (2011). Quantifying the impact of septic tank systems on eutrophication risk in rural headwaters. Environment International, 37(3), 644-653. doi: 10.1016/j.envint.2011.01.002. 